quan và chủ quan như đã phân tích ở trên cân phải được khắc phục và thay đổi để mang lại hiệu quả cao nhất cho người học.

Phương pháp giảng dạy đổi mới này có thể thay thế phương pháp giảng dạy truyền thống cho đối tượng sinh viên y khoa năm thứ 2 nhưng cần có sự điều chỉnh sao cho hợp lý để nâng cao chất lượng đào tạo và đạt được chuẩn đầu ra của Nhà trường.

Để có cơ sở cho việc điều chỉnh chương trình giảng dạy các module hệ cớ, chúng tôi khuyến nghị cần khảo sát phản hồi của sinh viên và giáo viên về từng module hê cơ quan, sự tương tác giữa giáo viên- sinh viên cũng như khối lượng kiến thức mà module truyền tải đến sinh viên.

\section{TÀI LIÊU THAM KHẢO}

1. Al- Damegh S, Baig LA. Comparison of an integrated problembased learning curriculum with the traditional discipline-based curriculum in KSA. J Coll Physicians Surg Pak 2005;15:605-8.

2. Custers EJ, Cate OT. Medical students' attitudes towards and perception of the basic sciences: a comparison between students in the old and the new curriculum at the University Medical Center Utrecht, The Netherlands. Med Educ 2003;36:1142-50

3.Ghosh S, Pandya HV. Implementation of integrated learning program in neurosciences during first year of traditional medical course: perception of students and faculty. BMC Med Educ 2008;8:44.

4. Muller JH, Jain $S$, Loeser $H$, Irby DM. Lessons learned about integrating a medical schoo curriculum: perceptions of students, faculty and curriculum leaders. Med Educ 2008;42:778-85.

5. Shimura $T$, Aramaki $T$, Shimizu $K$, Miyashita $\mathbf{T}$, Adachi $\mathbf{K}$, Teramoto A Implementation of integrated medical curriculum in Japenese medical schools. J Nippon Med Sch 2004;71:11-16.

6. Vyas $R$, Jacob $M$, Faith $M$, Isaac B, Rabi S, Sathishkumar $\mathbf{S}$, et al. An effective integrated learning programme in the first year of the medical course. Natl Med J India 2008;21:21-6.

7. Williams G, Lau A. Learning in practice. Reform of undergraduate medical teaching in the United Kingdom: a triumph of evangelism over common sense. Br Med J 2004;329:92-4

\title{
NGHIÊN CỨU GIÁ TRI CỦA CHỤP CLVT TRONG CHẨN ĐOÁN VÀ ĐIỀU TRI BẢO TỒN CHẤN THƯO'NG GAN
}

\section{TÓM TẮT}

Muc tiêu: Nghiên cứu giá trị của chup CLVT trong chẩn đoán và điều trị bảo tồn chấn thương gan. Đối tượng và phương pháp: Nghiên cứu mô tả cắt ngang hồi cứu, 51 bệnh nhân bị chấn thương gan, tại bệnh viện Nhân Dân 115 từ tháng $1 / 2017$ đến 12/2018. Kết quả: Đăcc điểm chung của đối tượng nghiên cứu: Nam 70,6\%; nữ 29,4\%; tuổi trung bình $33,65 \pm 14,17$; TNGT chiếm $82,4 \%$. Giá trị của cắt lớp vi tính trong điều trị bảo tồn chấn thương gan. Điều trị bảo tồn thành công $82,4 \%$; tắc mach $9,8 \%$; phấu thuật $7,8 \%$. Phẫu thuật và tắc mạch chủ yếu có độ tổn thương IV và V, chỉ 01 trường hợp đô III phẫu thuật do tổn thương rách túi mật đi kèm. Trong những trường hợp có huyết động ổn đinh: tổn thương độ I-II-III điêu trị bảo tồn 100\%; độ IV với $90 \%$ thành công và độ $V$ là $22,2 \%$. Tổn thương rách gan $100 \%$ bảo tồn thành công; dập gan 94,7\%; dập rách $72,4 \%$. Tỉ lệ điều trị bảo tồn thành công tî lệ nghich với mức độ dịch tự do trong ổ bung mức độ: nhiều $50 \%$; vưa $75 \%$ và ít $90,3 \%$. Kết luận: CLVT rất có giá trị trong chẩn đoán mức độ chấn thương gan,

*Trường Đại học Y khoa Phạm Ngọc Thạch. Chịu trách nhiệm chính: Đặng Vĩnh Hiệp

Email: hiepdv@pnt.edu.vn

Ngày nhận bài: 28/2/2021

Ngày phản biên khoa hoc: 25/3/2021

Ngày duyệt bài: 6/4/2021
Đặng Vĩnh Hiệp*

từ đó đưa ra các phương án điều trị phù hợp cho bệnh nhân. CLVT giúp chỉ định điều trị bảo tồn chấn thương gan được áp dụng nhiều hơn.

Tư khóa: Chấn thương gan, CLVT, điều trị bảo tồn chấn thương gan, nút mạch gan.

\section{SUMMARY}

\section{RESEARCH FOR VALUATION OF ABDOMINAL COMPUTED TOMOGRAPHY IN DIAGNOSTIC AND NONOPERATED TREATMENT OF LIVER TRAUMA}

Purpose: Research for valuation of abdominal computed tomography in diagnostic and nonoperated treatment of liver trauma. Subjects and method: Retrospective cross - sectional study of 51 liver trauma patients were diagnostic and treatment at People's Hospital 115, Ho Chi Minh City from 1/2017 to 12/2018. Results: Objective characteristics: Data from 51 patients, 36 males and 15 females (male/female $=2.4$ ) age for both sexes was 33,65 $\pm 14,17$. Traffic accident was $82.4 \%$. Valuation of abdiminal computed tomography for non - operated treatment liver trauma: Treatment success rate in liver trauma: $82.4 \%$ with non - operating, 9.8\% with embolization interventions, $7.8 \%$ with operation. Surgery and embolism mainly has damage in grade IV and V level, only 01 case of grade III surgery due to associated disection gallbladder trauma.. In the cases of hemodynamics stability: level I-II-III injury conservative treatment $100 \%$; Grade IV with $90 \%$ success and $\mathrm{V}$ level $22.2 \%$. Liver damage is 
$100 \%$ successfully preserved; liver stamping 94.7\%; stamping - tearing $72.4 \%$. The rate of treatment success is inversely proportional to the degree of abdiminal free fluid: high level with $50 \%$; medium level $75 \%$ and less level $90.3 \%$. Conclusion: Abdominal computed tomography is high value in diagnostic of grading hepatic trauma, thereby giving appropriate treatment options for patients. The presence of abdominal computed tomography make increasing of non- operation treatment for liver trauma.

Keywords; liver trauma, abdiminal computed tomography, non- operated treatment of liver trauma, liver arteries embolization.

\section{I. ĐĂTT VẤN ĐỀ}

Chấn thương gan (CTG) là một cấp cứu ngoại khoa thường gặp không chỉ ở Việt Nam mà còn trên thế giới, nguyên nhân chính là do tai nạn giao thông. Theo thống kê thì CTG đứng hàng thứ 2 sau chấn thương lách với 15-20\%, thường nằm trong bệnh cảnh đa chấn thương ${ }^{1}$.

Trước đây khi bệnh nhân(BN) bị CTG thường xác định là phẫu thuật, tuy nhiên, nhiều trường hợp quá chỉ định và có nhiều biến chứng sau mổ còn nặng nề hơn bản thân CTG, ngoài ra nhiều trường hợp CTG còn có thể tự cầm máu. Nghiên cứu thực hiện tại nhiều trung tâm trên thế giới cho thấy nhiêu trường hợp được điều trị bảo tồn thành công, thay vì phải phẫu thuật như trước đây. Lúc đâu áp dụng ở trẻ em, sau đó được áp dụng ở mọi lứa tuổi và hơn $80 \%$ trường hợp chấn thương gan. Tại bệnh viện Việt Đức, từ 1/2006 đến 12/2008, trên 287 bệnh nhân chấn thương gan được điêu trị bảo tồn không mổ có tỷ lệ thành cồng 93,9\%. Tại bênh viên Nhân Dân 115, từ 7/2005 đến 7/2007 điều trị bảo tồn không mố ở bệnh nhân chấn thương gan có huyết động ổn định đạt tỷ lệ thành công $96,4 \%{ }^{1}{ }^{2}$.

Vấn đề đăt ra thường xuyên ở các BN CTG nói riêng và các $B N$ chấn thương bụng kín nói chung là khi nào, loại tổn thương nào có chỉ định điều trị bảo tồn hay phẫu thuật, khi nào cân mổ cấp cứu, khi nào trì hoãn. Môtt trong những điều kiện cần thiết để có thể tiến hành chẩn đoán chấn thương gan và quyết định điều trị bảo tồn là phải có các phương tiện chẩn đoán và theo dõi bằng hình ảnh học như chụp cắt lớp vi tính và siêu âm. Siêu âm được áp dụng trong cấp cứu, nhanh, rẻ tiền, phổ biến nhưng phụ thuộc rất nhiều vào trang thiết bị và phương tiện người làm. Cắt lớp vi tính (CLVT) với nhiều sự tiến bô về độ dày lát cắt, số dãy đầu thu đa dãy đã thực sự trở thành phương tiện hữu hiệu cho không chỉ chấn đoán xác định, mức độ, phân độ tổn thương mà còn đánh giá sau điều trị một cách khách quan. Ngoài ra CLVT còn cho chúng ta cái nhìn tổng thể về các tổn thương tạng khác phối hợp trong ổ bụng ${ }^{3}{ }^{4}$. Vấn đề đặt ra là có sự tương quan giữa tốn thương CTG trên CLVT với kết quả điều trị bảo tồn hay không?, kỹ thuật chụp CLVT trong chấn thương gan có điểm gì chú ý?, vai trò có CLVT đa dãy trong CTG cần được phổ quát rộng hơn. Để trả lời cho các câu hỏi đó chúng tôi tiến hành nghiên cứu đề tài: "Nghiên cứu giá trị của chụp CLVT trong chẩn đoán và điều trị bảo tồn chấn thương gan tại BV Nhân Dân 115".

\section{II. ĐốI TƯỢNG VÀ PHƯƠ'NG PHÁP NGHIÊN CỨU}

2.1. Đối tượng nghiên cứu: Nghiên cứu được tiến hành trên 51 bệnh nhân được chẩn đoán chấn thương gan do chấn thương bụng kín được chụp CLVT ổ bụng và điều trị bảo tồn tại Bệnh viện Nhân Dân 115, từ tháng 01/2017 đến tháng 12/2018 thỏa tiêu chí nghiên cứu.

2.2. Phương pháp nghiên cứu:nghiên cứu mô tả cắt ngang với phương pháp thu thập số liệu hồi cứu.

\subsection{Quy trình nghiên cứu:}

Bước 1: Thu thập hồ sơ bệnh án theo một mẫu thống nhất cho tất cả các đối tượng thoả tiêu chí nghiên cứu.

Bước 2: Thu thập số liệu từ các đối tượng được lựa chọn theo tiêu chuẩn nghiên cứu: đặc điểm chung đối tượng, lâm sàng, dấu hiệu CLVT và phân độ AAST.

Bước 3: Xử lý và lưu giữ kết quả.

Bước 4: Thống kê và xử lý số liệu, phân tích đánh giá.

\section{KẾT QUẢ NGHIÊN CỨU}

3.1. Đặc điểm chung của đối tượng nghiên cứu. Qua nghiên cứu trên 51 bệnh nhân bị chấn thương gan, tại bệnh viện Nhân Dân 115. Trong đó nam $70,6 \%$; nữ $29,4 \%$; tuổi trung bình $33,65 \pm 14,17$; TNGT chiếm $82,4 \%$.

\subsection{Phương pháp điêuu trị}

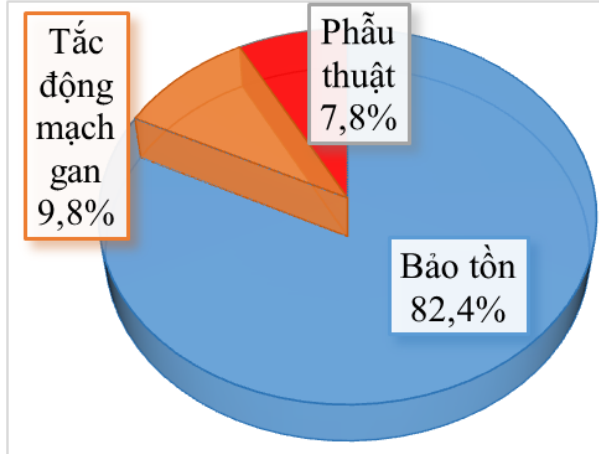

Biểu đồ 1. Phương pháp điều trị (n=51) 


\subsection{Giá trị của cắt lớp vi tính trong điêu trị bảo tồn chấn thương gan.}

Bảng 1. Phân bố độ chân thương gan theo phương pháp điều trị

\begin{tabular}{|c|c|c|c|c|c|c|c|c|}
\hline \multirow{2}{*}{ Mức độ } & \multicolumn{2}{|c|}{ Bảo tồn } & \multicolumn{2}{c|}{ Tắc mạch } & \multicolumn{2}{c|}{ Phâuu thuật } & \multicolumn{2}{c|}{ Cộng } \\
\cline { 2 - 8 } & $\mathbf{n = 4 2}$ & $\mathbf{\%}$ & $\mathbf{n = 5}$ & $\mathbf{\%}$ & $\mathbf{n = 4}$ & $\mathbf{\%}$ & $\mathbf{n = 5 1}$ & $\mathbf{\%}$ \\
\hline Độ I & 2 & 100 & 0 & 0 & 0 & 0 & 2 & 100 \\
\hline Độ II & 13 & 100 & 0 & 0 & 0 & 0 & 13 & 100 \\
\hline Độ III & 16 & 94,1 & 0 & 0 & 1 & 5,9 & 17 & 100 \\
\hline Độ IV & 9 & 90,0 & 0 & 0 & 1 & 10 & 10 & 100 \\
\hline Độ V & 2 & 22,2 & 5 & 55,6 & 2 & 22,2 & 9 & 100 \\
\hline
\end{tabular}

Nhân xét: Phẫu thuật và tắc mạch chủ yếu có độ tổn thương IV và V, chỉ 01 trường hợp độ III phẫu thuật do tổn thương rách túi mật đi kèm.

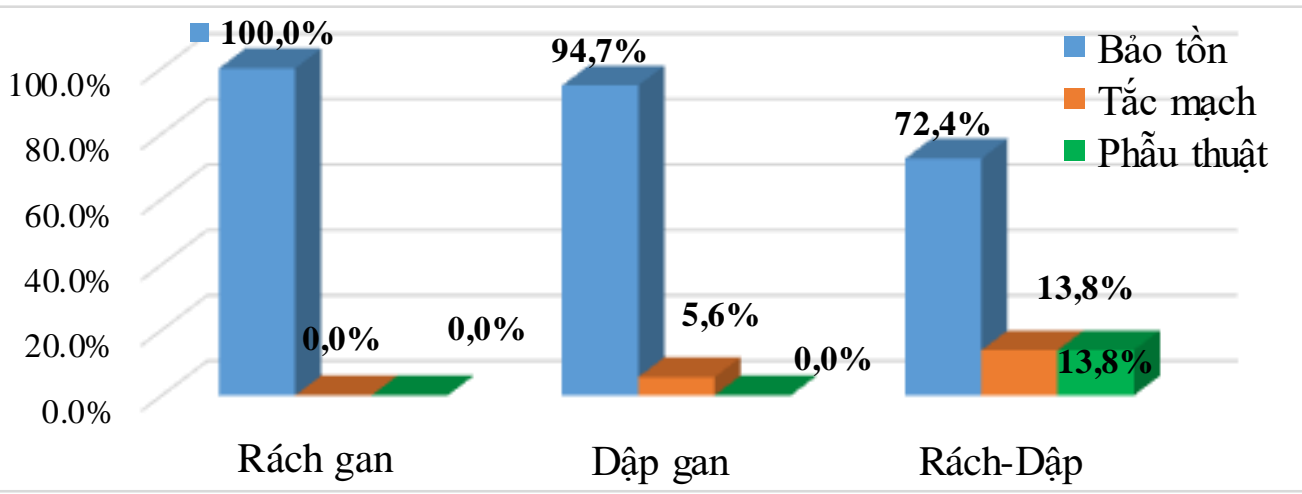

Biểu đồ 2. Đôi chiếu hình thái chấn thương gan theo điều trị (n=51)

Nhận xét: Cả 4 trường hợp rách gan bảo tồn $100 \%$; dập gan 18 trường hợp trong đó: bảo tồn $17(94,4 \%)$, tắc mạch 1 (5,6\%. Rách - dập kết hợp 29 trường hợp: bảo tồn 21 (72,4\%), tắc mạch 4 $(13,8 \%)$, phẫu thuất $4(13,8 \%)$.

Bảng 2. Phân bố mức độ dịch ổ bụng theo phương pháp điều trị

\begin{tabular}{|c|c|c|c|c|c|c|c|c|}
\hline \multirow{3}{*}{ Điêu trị } & \multicolumn{8}{|c|}{ Dịch tự do trong ố bụng } \\
\hline & \multicolumn{2}{|c|}{ Nhî̀u $(n=4)$} & \multicolumn{2}{|c|}{ Vừa(n=12) } & \multicolumn{2}{|c|}{ İt(n=31) } & \multicolumn{2}{|c|}{ Không có(n=4) } \\
\hline & Số TH & $\%$ & Số TH & $\%$ & Số TH & $\%$ & Số TH & $\%$ \\
\hline Bảo tồn & 2 & 50,0 & 9 & 75,0 & 28 & 90,3 & 3 & 75,0 \\
\hline Tắc mạch & 1 & 25,0 & 1 & 8,3 & 2 & 6,5 & 1 & 25,0 \\
\hline Phầu thuật & 1 & 25,0 & 2 & 16,7 & 1 & 3,2 & 0 & 0 \\
\hline & 4 & 100 & 12 & 100 & 31 & 100 & 4 & 100 \\
\hline
\end{tabular}

Nhân xét: Trong 4 trường hợp có dịch tự do trong ổ bụng mức độ nhiều thì chỉ có 02 trường hợp được điêu trị bảo tồn (50\%).

Bảng 3. Phân bố mức độ dịch ổ bụng với truyền máu

\begin{tabular}{|c|c|c|c|c|c|c|c|c|c|c|}
\hline \multirow{3}{*}{$\begin{array}{c}\text { Truyền } \\
\text { máu }\end{array}$} & \multicolumn{10}{|c|}{ Dịch tự do trong ố bụng $(n=51)$} \\
\hline & \multicolumn{2}{|c|}{ Nhiêuu(n=4) } & \multicolumn{2}{|c|}{ Vừa(n=12) } & \multicolumn{2}{|c|}{ Itt(n=31) } & \multicolumn{2}{|c|}{ Không có( $n=4)$} & \multicolumn{2}{|c|}{ Cộng } \\
\hline & Số TH & $\%$ & Số TH & $\%$ & Số TH & $\%$ & Số TH & $\%$ & Số TH & $\%$ \\
\hline$C$ & 3 & 75,0 & 3 & 25,0 & 3 & 9,7 & 1 & 25,0 & 10 & 19,6 \\
\hline Không & 1 & 25,0 & 9 & 75,0 & 28 & 90,3 & 3 & 75,0 & 41 & 80,4 \\
\hline Cộng & 4 & 100 & 12 & 100 & 31 & 100 & 4 & 100 & 51 & 100 \\
\hline
\end{tabular}

Nhận xét: Có $75 \%$ đối tượng nghiên cứu có dịch tự do trong ố bụng mức độ nhiều được truyền máu trong quá trình điều trị.

Bảng 4. Đối chiếu thời gian nằm viện với độ tổn thương gan

\begin{tabular}{|c|c|c|c|c|c|c|c|c|}
\hline \multirow{3}{*}{ Mức độ } & \multicolumn{8}{|c|}{ Thời gian nằm viện $(n=51)$} \\
\hline & \multicolumn{2}{|c|}{$\leq 7$ ngày } & \multicolumn{2}{|c|}{ 8-14 ngày } & \multicolumn{2}{|c|}{$\geq 15$ ngày } & \multicolumn{2}{|c|}{ Cộng } \\
\hline & $\mathbf{n}$ & $\%$ & $\mathrm{n}$ & $\%$ & $n$ & $\%$ & $\mathbf{n}$ & $\%$ \\
\hline Đô̂ I & 2 & 100 & 0 & 0 & 0 & 0 & 2 & 100 \\
\hline Độ II & 11 & 84,6 & 2 & 15,4 & 0 & 0 & 13 & 100 \\
\hline Độ III & 14 & 82,4 & 0 & 0 & 3 & 17,6 & 17 & 100 \\
\hline
\end{tabular}




\begin{tabular}{|c|c|c|c|c|c|c|c|c|}
\hline Độ IV & 4 & 40,0 & 3 & 30,0 & 3 & 30,0 & 10 & 100 \\
\hline Độ̣ V & 2 & 22,2 & 6 & 66,7 & 1 & 11,1 & 9 & 100 \\
\hline Cộng & $\mathbf{3 3}$ & $\mathbf{6 4 , 7}$ & $\mathbf{1 1}$ & $\mathbf{2 1 , 6}$ & $\mathbf{7}$ & $\mathbf{1 3 , 7}$ & $\mathbf{5 1}$ & $\mathbf{1 0 0}$ \\
\hline
\end{tabular}

Nhận xét: Tỉ lệ nằm viện $\geq 15$ ngày chủ yếu ở độ tốn thương III và IV $(13,7 \%)$. Tỉ lệ nằm viện $\leq 7$ ngày cao nhất trong số đối tượng nghiên cứu chiếm $64,7 \%$. Tỉ lệ nằm viện $8-14$ ngày chiếm $21,6 \%$.

\section{BÀN LUẬN}

4.1. Đặc điểm chung của đối tượng nghiên cứu: Trong nghiên cứu của chúng tôi cho thấy đa phần bệnh nhân trẻ tuổi và hay gặp nam giới, nguyên nhân chính thường là tai nạn giao thông. Điều này tương đồng với tác giả Trần Vĩnh Hưng (2008) và Vũ Thanh Xuân (2009), cũng như tác giả Mirvis (1989) ${ }^{2}, 3,4$. Điều này có thể giải thích do lối sống và thói quen sinh hoạt của đối tượng nghiên cứu.

4.2. Phương pháp điêuu trị: Theo kết quả nghiên cứu trong 3 phương pháp được áp dụng điêu trị chấn thương gan ở đối tượng nghiên cứu thì phương pháp bảo tồn chiếm tỉ lệ cao nhất với $82,4 \%$ với 42 bệnh nhân được điều trị bằng phương pháp này. Tiếp đến là điều trị bằng phương pháp tắc động mạch gan cho 05 bệnh nhân với tỉ lể là $9,8 \%$ và chỉ có 4 bệnh nhân phải điều trị phấu thuật chiếm tỉ lệ $7,8 \%$. Kết quả nghiên cứu của chúng tôi cũng tương đồng với tác giả Poletti với tỷ lệ điều trị bảo tồn là $80 \%{ }^{5}$. Đa số các tác giả đểu thống nhất rằng huyết động là yếu tố quyết định thái độ xử trí hơn là mức độ chấn thương gan.

4.3. Giá trị của cắt lớp vi tính trong điêu trị bảo tồn chấn thương gan: Chụp CLVT đã góp phần làm thay đổi thái độ điểu trị chấn thương gan do khả năng chẩn đoán chính xác DTDOB, đo lượng dịch tiên lượng được lượng máu mất. CLVT cho thấy chính xác vị trí, mức độ, tính chất tổn thương giải phẫu, phát hiện các tổn thương phối hợp khác trong ổ bụng và sau phúc mạc, cùng các triệu chứng lâm sàng loại trừ các tổn thương phải mổ.

CLVT chẩn đoán chấn thương gan với độ nhạy $97,9 \%$; độ đặc hiệu $100 \%$; độ đặc hiệu 100\%; giá trị dự báo dương tính $100 \%$; độ chính xác $98 \%{ }^{6}$.

Tác giả Buci S. và cộng sự cho biết tỉ lệ thành công của điều trị bảo tồn theo mức độ tổn thương như sau: độ I $(38,4 \%)$, độ II $(30,1 \%)$, độ III $(28,8 \%)$ và độ IV $(2,7 \%)$. Có một mối tương quan điêuu trị bảo tồn thành công với mức độ tổn thương gan $(p<0,00001)$, chấn thương trong ổ bụng liên quan $(p=0,00051)$, và các biến chứng $(z=2.3169, p=0,02051)$. Tỷ lệ tử vong chung của chấn thương gan là 13,2\%”7 .
Từ khi có sự ra đời của kỹ thuâtt chụp CLVT đã góp phần làm thay đổi ngành chẩn đoán hình ảnh. CLVT đã khẳng định được vai trò và giá trị của chẩn đoán hình ảnh trong chẩn đoán và quyết định phương pháp điều trị tối ưu. Từ những năm 1980 với việc chẩn đoán tổn thương gan bằng chụp CLVT trong chấn thương bụng kín đã làm thay đổi quan niệm trong điều trị vỡ gan do chấn thương. Trước khi có chụp CLVT hâuu hết các trường hợp võ̃ gan chấn thương đều được điều trị phẩu thuật. Chụp CLVT để chẩn đoán, đánh giá mức độ tổn thương, theo dõi điều trị, phát hiện biến chứng. Chụp CLVT phân loại chấn thương gan dựa trên thang điểm tổn thương gan của AAST ${ }^{3,5}$.

\section{KẾT LUÂ̂N}

CLVT rất có giá trị trong chẩn đoán mức độ chấn thương gan, từ đó đưa ra các phương án điều trị phù hợp cho bệnh nhân. Vai trò của CLVT thể hiện từ chẩn đoán cho đến theo dõi sau điều trị. Việc có CLVT làm cho chỉ định điều trị bảo tồn chấn thương gan được áp dụng nhiều hơn.

\section{TÀI LIÊUU THAM KHẢO}

1. Trần Bình Giang (2014), "Chấn thương gan" Chẩn thương bụng, Nhà xuất bản Khoa Học và Kŷ́ Thuật, Hà Nội, tr: 53-138.

2. Trần Vĩnh Hưng, Nguyễn Phan Tú Dung (2008), "Điêu trị bảo tồn không mổ chấn thương gan do chấn thương bụng kín", Y học Việt Nam, số 1, tr: 23 - 33 .

3. Mirvis SE., Whitley NO., Vainwright JR, et al (1989), "Blunt hepatic trauma in adults: CT-based classification and correlation with prognosis and treatment", Radiology. 1989 Apr;171(1):27-32.

4. Vũ Thanh Xuân (2009), Nghiên cưuu hình ảnh cắt lớp điện toán và siêu âm trong chẩn đoán chấn thương gan được điều trị bảo tôn, Luận văn Bác sĩ chuyên khoa cấp 2, Đại học Y Dược TP. Hồ Chí Minh.

5. Poletti PA., Mirvis SE., Shanmuganathan K. et al (2000), "CT Criteria for Management of Blunt Liver Trauma: Correlation with Angiographic and Surgical Findings", Radiology; 216:418-427.

6. Ngô Quang Duy, Nguyến Văn Hải (2013), "Đánh giá kết quá điều trị bảo tồn không mổ vớ gan chấn thương", Y học TP. Hồ Chí Minh, tập 17, số 6, tr. 166-171.

7. Buci S., Torba M., Gjata A., et al (2017), "The rate of success of the conservative management of liver trauma in a developing country", World Journal of Emergency Surgery (2017) 12:24. 